Federal Reserve Bank of Dallas

Globalization and Monetary Policy Institute

Working Paper No. 131

http://www.dallasfed.org/assets/documents/institute/wpapers/2012/0131.pdf

\title{
Core Import Price Inflation in the United States*
}

\author{
Janet Koech \\ Federal Reserve Bank of Dallas \\ Mark A. Wynne \\ Federal Reserve Bank of Dallas
}

November 2012

\begin{abstract}
The cross-section distribution of U.S. import prices exhibits some of the fat-tailed characteristics that are well documented for the cross-section distribution of U.S. consumer prices. This suggests that limited-influence estimators of core import price inflation might outperform headline or traditional measures of core import price inflation. We examine whether limited influence estimators of core import price inflation help forecast overall import price inflation. They do not. However, limited influence estimators of core import price inflation do seem to have some predictive power for headline consumer price inflation in the medium term.
\end{abstract}

JEL codes: E31, E37

\footnotetext{
* Janet Koech, Federal Reserve Bank of Dallas, Research Department, 2200 N. Pearl Street, Dallas, TX 75201. 214-922-5053. janet.koech@dal.frb.org. Mark A. Wynne, Federal Reserve Bank of Dallas, Research Department, 2200 N. Pearl Street, Dallas, TX 75201. 214-922-5159. mark.a.wynne@dal.frb.org. The authors would like to thank two anonymous referees for helpful comments and suggestions. The views in this paper are those of the authors and do not necessarily reflect the views of the Federal Reserve Bank of Dallas or the Federal Reserve System.
} 


\section{Introduction}

As the United States has become more open to international trade, analysts have increasingly paid more attention to developments in import prices as sources of inflationary or disinflationary pressures in the U.S. economy. In the earlier part of the last decade, the integration of China into the global trading system was viewed by many as an important source of disinflationary pressures on the U.S. economy. However, as the decade evolved, analysts realized that the impact of China and other rapidly growing emerging market economies was more subtle, given the voracious demand of these economies for oil and other raw materials. Far from being a source of permanent disinflationary pressures that always operated in just one direction, it was soon realized that the impact of these emerging market economies on inflation dynamics in the advanced economies was more complicated. ${ }^{1}$

The benchmark model used by most central banks for thinking about short run inflation dynamics is of course the Phillips Curve which has its origin in the empirical relationship first documented by Phillips (1958). In the Phillips Curve framework, resource utilization or slack is seen as being useful in predicting future inflation. Defining and measuring the relevant measure of slack or resource utilization is challenging. Some researchers rely on purely statistical measures, such as deviations from a deterministic or time-varying trend of some sort. Others employ measures that have some basis in economic theory, such as production function measures or deviations from some measure of the frictionless level of activity. Some of these issues are reviewed in Wynne and Solomon (2007). Then there is also the question of whether the relevant measure of slack should be measured at the domestic or global level when an economy is open to international trade. See, for example, the discussion in Martínez-García and Wynne (2010, 2012).

Phillips also recognized the importance of import prices as a determinant of (wage)

\footnotetext{
${ }^{1}$ See for example Charles Bean's remarks at the Jackson Hole symposium in 2006, and specifically his observation that "While the Sino-Indian development miracle probably has some way to run, the neartripling of oil prices over the past couple of years, and the rise in commodity prices more generally, is surely itself in large part a reflection of the rapid industrialization of China and the other emerging economies. The fact that the rise in oil prices is the flip side of the globalization shock to me renders highly suspect the practice of focusing on measures of core inflation that strip out energy prices while retaining the falling goods prices." (Bean, 2006, pp. 307-308).
} 
inflation in his original study, but much of the early literature that developed in the wake of his seminal contribution tended to omit such prices. The experience of the 1970s changed all that, and the revised versions of the Phillips Curve model that emerged in the wake of the oil shocks tended to include, in addition to terms that controlled for inflation expectations, terms that captured foreign influences on domestic prices. ${ }^{2}$

The concept of core inflation was developed in the 1970s as it became apparent that some movements in the headline inflation numbers tracked by central banks might be due to transitory developments in relative prices in specific markets to which it might not be appropriate for monetary policy to respond. One-time or transitory movements in food or energy prices from month to month, for example, were seen as providing little or no information about the evolution of inflation over the longer horizons that are of more interest to central bankers, and as these prices became more volatile, the original (and still widely used) measures of core inflation simply excluded them. Moreover, core inflation was seen as providing useful information about where headline inflation was headed in the future, or, as being helpful in predicting headline inflation.

Research on the measurement of core inflation received a major boost in the 1990s due to the work of Bryan and Pike (1991) and Bryan and Cecchetti (1994), who proposed a more systematic approach to the measurement of core inflation, motivated in part by the large literature on price stickiness. They were the first to propose the use of limited influence estimators such as the trimmed mean or weighted median of the cross-section distribution of price changes to measure core inflation. The limited influence estimator approach has subsequently proven very influential in the literature on core inflation (see, inter alia, the papers by Roger (1997), Vega and Wynne (2003) and Dolmas (2005)).

To date, all of the literature on core inflation measurement has been concerned with core consumer price inflation. In this paper we explore the use of limited influence estimators to measuring core import price inflation, and specifically, whether such estimators of core import price inflation can improve our ability to forecast either headline import price or headline consumer price inflation in the U.S. This appears to be a relatively under-researched topic,

\footnotetext{
${ }^{2}$ See for example Gordon (2011).
} 
which is a bit surprising, as most of the relative price shocks that seem to necessitate the construction of core inflation measures are to the prices of goods that are traded in global markets. Moreover, the prices of these goods are largely determined by global rather than purely domestic factors. We find that the properties of the cross-section distribution of U.S. import prices are similar to those of the cross-section distribution of U.S. consumer prices, and specifically, that the cross-section distribution of import prices exhibits the same kind of excess kurtosis found in the cross-section distribution of import prices. Thus, limitedinfluence estimators of core import price inflation might be superior along some dimensions to the simple mean or the traditional exclusion-type measure of core import price inflation. We find that while the limited influence estimator of core import price inflation does not help in predicting headline import price inflation, it does have some incremental predictive power for headline consumer price inflation.

\section{Data}

Our objective in this paper is to see whether trimmed mean measures of core import price inflation have any predictive power for inflation at the consumer level in the U.S. A necessary first step is to look at the properties of the cross section distribution of import price changes to see if the efficiency gains that are known to come with trimming are likely to be realized. Limited influence estimators of central tendency are superior to a simple mean when the cross section distribution of price changes exhibits excess kurtosis, or has "fat tails" (see Dolmas (2005)). High kurtosis makes the sample mean a less efficient and less robust estimator of the population mean. The mean of the Normal distribution, with a kurtosis of 3 , is most efficiently estimated using the sample mean because equal weight is placed on all observations. For distributions with kurtosis greater than 3, the most efficient estimators place relatively low weights on observations in the tails. A trimmed-mean computation is such an estimator as it gives zero-weights to some proportion at each end of the distribution. A finding of skewness that is more than zero would suggest that trimmings should not be constrained to symmetric ones. 
Let us define $\mu_{i, t \mid t-1}=\ln \left(p_{i, t}^{m} / p_{i, t-1}^{m}\right)$ as the month-over-month percentage change in the $i$ 'th import price series $p_{i, t}^{m}$ at date $t$. Our basic data on import price indexes are drawn from the monthly U.S. Import and Export Price Indexes report, and specifically from Table 5 "U.S. Import Price Indexes Classified by the Harmonized System". ${ }^{3}$ While the Harmonized classification system publishes data up to the four digit level, we limit ourselves to the threedigit level to maximize time series coverage (many of the series at the four digit level have short time series histories or have been discontinued). Table 1 lists the 45 raw data series we work with, along with their relative importance as of June 2012. Our full sample of data on import prices runs from October 1993 through July 2012, and the sample statistics on the mean of month-over-month import price changes, standard deviation and first order autocorrelation coefficients are also reported for this period.

One point to note is the very large weight or relative importance of the price of "Mineral Fuels, Bituminous Substances, Mineral Waxes". This category includes crude oil, petroleum oils and petroleum gases. Unfortunately the Bureau of Labor Statistics does not publish relative importance for the three sub-component (four-digit) categories, so we have to work with the more aggregated series with the larger weight. While this is less than desirable from the perspective of computing trimmed means, it is analogous to the problem that arises when trimming the component series of the Consumer Price Index and the large weight that is attached to owner-occupied housing in that index. In June 2012, for example, the expenditure category "Owner's equivalent rent of primary residence" had a relative importance of 23.8 percent in the Consumer Price Index, not very different from the 21.7 percent relative importance of "Mineral fuels" in the import price index.

Let us also define $\bar{\mu}_{t \mid t-1}=\sum_{i} w_{i, t} \mu_{i, t \mid t-1}$ as the weighted mean of the cross section distribution of import price changes at date $t$ with weights $w_{i, t}$. Note that the weights are indexed by $t$ and are time varying. The weights we use are the relative importances of each item published in the monthly price report. The $q$ 'th higher-order central moment of the cross section distribution of price changes at date $t$ is then defined as $m_{q, t \mid t-1}=\sum w_{i, t}\left(\mu_{i, t \mid t-1}-\bar{\mu}_{i, t \mid t-1}\right)^{q}$. The

\footnotetext{
${ }^{3}$ The monthly report also includes import prices classified by end use category and by NAICS.

${ }^{4}$ Recall that Bryan and Cecchetti (1994) worked with 36 component series of the CPI.
} 


\section{Table 1: Import Index Components, Relative Importance and Import Prices Summary Statistics for the Period 1993:10 to 2012:07}

\begin{tabular}{|c|c|c|c|c|c|c|c|c|}
\hline & \multirow[b]{2}{*}{ Products } & \multirow{2}{*}{$\begin{array}{l}\text { Weights } \\
\text { June '12 }\end{array}$} & \multicolumn{2}{|c|}{ Mean } & \multicolumn{2}{|c|}{ Std. Dev. } & \multicolumn{2}{|c|}{ AR1 } \\
\hline & & & SA & NSA & $\mathrm{SA}$ & NSA & $\mathrm{SA}$ & NSA \\
\hline 1 & Mineral Fuels, Bituminous Substances & 21.72 & 0.95 & 1.00 & 6.21 & 6.67 & 0.46 & 0.48 \\
\hline 2 & Specialized Machinery \& Computer Equipment & 12.68 & -0.14 & -0.14 & 0.34 & 0.36 & 0.41 & 0.42 \\
\hline 3 & Elec Mach \& Eqpt, Sound \& TV Recorders & 12.45 & -0.17 & -0.17 & 0.36 & 0.38 & 0.19 & 0.20 \\
\hline 4 & Motor Vehicles \& Their Parts & 9.57 & 0.10 & 0.10 & 0.22 & 0.26 & 0.31 & 0.29 \\
\hline 5 & Pharmaceutical Products & 3.08 & 0.16 & 0.14 & 0.81 & 0.90 & 0.17 & 0.17 \\
\hline 6 & Optical, Photographic, Med Instruments & 3.00 & 0.00 & -0.01 & 0.38 & 0.41 & 0.17 & 0.15 \\
\hline 7 & Organic Chemicals & 2.46 & 0.17 & 0.17 & 1.16 & 1.23 & 0.22 & 0.18 \\
\hline 8 & Apparel, Knitted or Crocheted & 2.05 & 0.04 & 0.04 & 0.42 & 0.45 & -0.04 & -0.01 \\
\hline 9 & Furniture \& stuffed furnishings/Lights \& nesoi & 2.00 & 0.06 & 0.06 & 0.39 & 0.42 & 0.19 & 0.19 \\
\hline 10 & Apparel \& clothing - Not Knitted or Crocheted & 1.96 & 0.09 & 0.09 & 0.42 & 0.44 & 0.24 & 0.21 \\
\hline 11 & Plastics \& articles thereof & 1.92 & 0.17 & 0.17 & 0.81 & 0.86 & 0.34 & 0.35 \\
\hline 12 & Toys, Games, \& Sports Equip & 1.55 & 0.00 & 0.00 & 0.31 & 0.33 & 0.09 & 0.09 \\
\hline 13 & Articles of Iron or Steel & 1.44 & 0.21 & 0.21 & 0.91 & 0.95 & 0.70 & 0.68 \\
\hline 14 & Rubber \& Articles Thereof & 1.24 & 0.20 & 0.21 & 1.06 & 1.15 & 0.36 & 0.37 \\
\hline 15 & Footwear \& Parts of Such Articles & 1.15 & 0.08 & 0.09 & 0.28 & 0.31 & 0.23 & 0.17 \\
\hline 16 & Iron \& Steel & 1.14 & 0.43 & 0.45 & 2.47 & 2.68 & 0.69 & 0.70 \\
\hline 17 & Inorganic Chemicals & 0.97 & 0.75 & 0.75 & 3.49 & 3.71 & 0.32 & 0.32 \\
\hline 18 & Beverages, Spirits \&Vinegar & 0.81 & 0.13 & 0.13 & 0.46 & 0.49 & 0.07 & 0.07 \\
\hline 19 & Paper/Paperboard \& Pulp Products & 0.81 & 0.12 & 0.12 & 1.17 & 1.23 & 0.53 & 0.50 \\
\hline 20 & Aircraft, Spacecraft \& Parts Thereof & 0.72 & 0.15 & 0.15 & 0.38 & 0.40 & 0.01 & 0.01 \\
\hline 21 & Aluminum\& Articles Thereof & 0.71 & 0.26 & 0.28 & 2.33 & 2.52 & 0.50 & 0.48 \\
\hline 22 & Made-Up or Worn Textile Articles & 0.64 & 0.05 & 0.05 & 0.91 & 0.95 & 0.11 & 0.12 \\
\hline 23 & Fish \& Crustaceans, Molluscs & 0.61 & 0.20 & 0.21 & 1.32 & 1.51 & 0.22 & 0.20 \\
\hline 24 & Articles of Leather; Travel Goods, Bags & 0.55 & 0.12 & 0.12 & 0.42 & 0.47 & 0.09 & 0.07 \\
\hline 25 & Fertilizers & 0.50 & 1.10 & 1.10 & 4.50 & 4.50 & 0.38 & 0.38 \\
\hline 26 & Miscellaneous Chemical Products & 0.48 & -0.04 & -0.04 & 0.96 & 1.01 & 0.28 & 0.28 \\
\hline 27 & Edible Fruit \& Nuts;Peel of Citrus Friuts or Melon & 0.48 & 0.21 & 0.22 & 3.22 & 3.63 & -0.05 & -0.01 \\
\hline 28 & Copper \& Articles Thereof & 0.46 & 0.65 & 0.55 & 4.15 & 4.64 & 0.48 & 0.49 \\
\hline 29 & Essential Oils \& Resinoids & 0.42 & 0.18 & 0.18 & 0.90 & 0.93 & 0.16 & 0.16 \\
\hline 30 & Coffee, Tea, mate \& Spices & 0.42 & 0.71 & 0.70 & 5.93 & 6.26 & 0.13 & 0.19 \\
\hline 31 & Miscellaneous Articles of Base Metal & 0.42 & 0.17 & 0.17 & 0.59 & 0.65 & 0.01 & -0.03 \\
\hline 32 & Tools, Implements, Cutlery of Base Metal & 0.37 & 0.12 & 0.10 & 0.48 & 0.58 & 0.21 & 0.19 \\
\hline 33 & Preps of Vegetables, Fruit, Nuts & 0.35 & 0.24 & 0.23 & 1.77 & 1.89 & 0.23 & 0.24 \\
\hline 34 & Edible Vegetables, Roots \& Tubers & 0.33 & 1.20 & 1.17 & 12.24 & 13.71 & -0.30 & -0.25 \\
\hline 35 & Glass \& Glassware & 0.29 & 0.12 & 0.13 & 0.72 & 0.75 & -0.09 & -0.07 \\
\hline 36 & Meat \& Edible Offal & 0.27 & 0.28 & 0.28 & 2.02 & 2.29 & 0.18 & 0.20 \\
\hline 37 & Articles of Stone, Plaster, Cement, Mica & 0.25 & 0.18 & 0.18 & 0.88 & 0.88 & -0.05 & -0.05 \\
\hline 38 & Preps of Cereals, Flour, Starch or Milk & 0.23 & 0.43 & 0.47 & 1.75 & 2.02 & 0.24 & 0.21 \\
\hline 39 & Ceramic Products & 0.23 & 0.17 & 0.17 & 0.68 & 0.76 & 0.03 & 0.02 \\
\hline 40 & Miscellaneous Manufactured Articles & 0.21 & 0.12 & 0.12 & 0.87 & 0.95 & -0.06 & -0.04 \\
\hline 41 & Clocks \& Watches \& Parts Thereof & 0.20 & 0.12 & 0.11 & 0.74 & 0.78 & 0.09 & 0.08 \\
\hline 42 & Tanning/Dyeing Extracts; Pigments;Putty & 0.19 & 0.36 & 0.36 & 2.44 & 2.44 & 0.10 & 0.10 \\
\hline 43 & Pulp Wood, Waste Paper \& Paperboard & 0.19 & 0.59 & 0.59 & 3.25 & 3.25 & -0.30 & -0.30 \\
\hline 44 & Cocoa \& Cocoa Preparations & 0.18 & -0.64 & -0.64 & 3.60 & 3.60 & -0.22 & -0.22 \\
\hline 45 & Nickle \& Articles Thereof & 0.13 & 0.19 & 0.19 & 6.98 & 6.98 & 0.31 & 0.31 \\
\hline
\end{tabular}


scaled third and fourth moments (skewness and kurtosis) are then defined as $S_{t}=\frac{m_{3, t \mid t-1}}{\left(m_{2, t \mid t-1}\right)^{(3 / 2)}}$ and $K_{t}=\frac{m_{4, t \mid t-1}}{\left(m_{2, t \mid t-1}\right)^{2}}$. Table 2 lists some summary statistics for the average cross-section distributions of the month-over-month changes of U.S. import price indexes over the period 1993:10-2012:7. For comparison we report the comparable statistics for the cross section distribution of the month-over-month changes in the components of the CPI over the same period. The table shows the average value over the sample period of the cross-section mean, standard deviation, skewness and kurtosis of the monthly price changes that go into both indexes. Note that while the mean rates of import price inflation and consumer price inflation over the sample are of comparable order of magnitude, the volatility of import prices (as measured by the standard deviation of the cross-section distribution) is more than twice that of consumer prices. Both measures of prices exhibit high kurtosis and positive skewness (the sample skewness of 0.698 in the consumer price series is more than twice the value of 0.346 reported by Bryan and Cecchetti in their original study).

\section{Table 2: Summary Statistics of the Cross-Sectional Distribution of Import and Consumer Price Changes for the Period 1993:10 to 2012:7}

\begin{tabular}{|l|c|c|c|c|}
\hline & Mean & Std. Deviation & Skewness & Kurtosis \\
\hline Import Price Index & 0.216 & 2.476 & 0.522 & 12.834 \\
\hline Consumer Price Index & 0.222 & 1.084 & 0.698 & 9.977 \\
\hline
\end{tabular}

Figure 1 plots the evolution of the standard deviation, skewness and kurtosis of the cross section distribution of monthly changes of U.S. import and consumer price indexes over the sample time period. Not surprisingly, the figure shows that import prices are a lot more volatile than consumer prices, but that the skewness and kurtosis of the two distributions are more comparable.

The construction of the trimmed mean inflation rate of import prices is standard. ${ }^{5} \mathrm{We}$ start by sorting the prices at a particular date from lowest to highest and then define the cumulative weight from the smallest price change to the $i$ 'th highest as is defined as $W_{i, t}=$

\footnotetext{
${ }^{5}$ See Appendix for steps of calculating trimmed mean measures of inflation.
} 
$\sum_{j=1}^{i} w_{(j), t}$ where $w_{(j), t}$ denotes the sorted $j$ 'th weight at date $t$ and by definition $1>w_{(j), t} \geqq 0$. We then define an index set $I_{\alpha}=\left\{i: \alpha<W_{i, t}<1-\alpha\right\}$. The $\alpha$ percent (symmetric) trimmed mean import price inflation rate is then defined as $\bar{\mu}_{t \mid t-1}(\alpha)=\frac{1}{1-2 \alpha} \sum_{i \in I_{\alpha}} w_{(i), t} \mu_{i, t \mid t-1}$. The $\left(\alpha^{T}, \alpha^{B}\right)$ asymmetric trimmed mean is defined analogously with $I_{\alpha^{T}, \alpha^{B}}=\left\{i: \alpha^{B}<W_{i, t}<\right.$ $\left.\alpha^{T}\right\}$ and $\bar{\mu}_{t \mid t-1}\left(\alpha^{T}, \alpha^{B}\right)=\frac{1}{1-\alpha^{T}-\alpha^{B}} \sum_{i \in I_{\alpha}} w_{(i), t} \mu_{i, t \mid t-1}$.

The choice of how much to trim from each tail of the distribution is determined using the same criterion employed by Bryan and Cecchetti (1994). They use a 36-month-centered moving average of monthly inflation rates as a proxy for the trend rate of inflation, and choose how much to trim from the tails of the cross-section distribution so as to minimize the deviation of the trimmed mean from this measure of trend. Using this criterion, the optimal trimming discards 48 percent from the left tail and 39 percent from the right tail, giving a total of 87 percent trimming. Bryan and Cecchetti also consider trimmed mean measures with the lowest variance or with the highest persistence (as measured by the first order autocorrelation). A trim of 40 percent off the bottom and 42 percent from the top has the least variance, and one with 37 percent off the bottom and 29 percent off the top has the highest autocorrelation. Both trimmings are considered for our regressions. The Cleveland Fed uses a median price change (following the recommendation of Bryan and Pike, 1991) as representative of underlying inflation trends. Instead of calculating a weighted average of all price changes in the components of the price index, they look at the median price change - or the price that's right in the middle of the list of all price changes. This is essentially trimming 50 percent off the top and 50 percent off the bottom and reporting the remaining price changes. Symmetric trimmings of up to 15 percent (in increments of 5 percent) from each tail of import price changes are also considered in forecasting headline CPI inflation and import inflation at different horizons.

Insert Figure 1 here 


\section{Does trimmed mean import price inflation help fore- cast inflation?}

Following Stock and Watson (1999), D'Agostino and Surico (2009) and others, the benchmark model we use to investigate the ability of some candidate series $x_{t}$ to help forecast inflation is the following

$$
\pi_{t+h \mid t}=\phi+\gamma(L) \pi_{t \mid t-1}+\beta(L) x_{t}+\theta(L) \varepsilon_{t+h}
$$

where $\pi_{t+h \mid t}=(1200 / h) \ln \left(p_{t+h} / p_{t}\right)$ is the $h$-period annualized increase in the price level $p_{t}, x_{t}$ is the variable whose predictive power we are interested in, $\phi$ is a constant and $\gamma(L)$, $\beta(L)$ and $\theta(L)$ are polynomials in the lag operator $L$. This equation allows us to ask as of each date $t$ whether - when it comes to forecasting inflation $h$ months in the future - there is any incremental predictive power in the series $x_{t}$ over and above what we obtain from the time series behavior of inflation itself. We use different specifications for the $x_{t}$ variable and compare the performance of each in predicting annualized U.S. headline consumer and import price inflation at different forecast horizons. The benchmark univariate forecasts, where forecasts of annualized headline CPI and import price inflation are based exclusively on lags of the first difference of the logs of the CPI, and import price index are generated from the ARMA model

$$
\pi_{t+h \mid t}=\phi+\gamma(L) \pi_{t \mid t-1}+\theta(L) \varepsilon_{t+h}
$$

We then compare the accuracy of the forecasts generated by this simple model with those generated by the more general models that include different measures of import price inflation, specifically a measure of all import price inflation, a measure of core import price inflation where core is defined using the traditional exclusion approach and excludes the

prices of petroleum imports, and finally different measures of trimmed mean import price 
inflation. ${ }^{6}$ We perform a pseudo out-of-sample forecasting exercise for each model over the horizons $h=1,3,6,9,12,18$, and 24 months. The estimation sample begins in October 1993, and ends in December of 2001. ${ }^{7}$

The first pseudo out-of-sample forecasting period begins in January 2002 and ends in June 2012 - and includes the forecasts of the Great Recession period of 2008 and 2009. The second forecasting period begins in January 2002 and ends in December 2007 - capturing the performance of the model during the Great Moderation period when prices were less volatile. We use recursive samples and evaluate the forecast accuracy using the mean square forecasting error statistic (MSFE), where $\hat{\pi}_{t+h \mid t}$ is the forecasted headline inflation, $\pi_{t+h \mid t}$ is the realized inflation rate between $t$ and $t+h$, and $T$ is the sample size: $M S F E=$ $\frac{1}{T-h} \sum_{t=1}^{T-h}\left(\hat{\pi}_{t+h \mid t}-\pi_{t+h \mid t}\right)^{2}$

\section{Results}

We assess the predictive power of each model for both import and CPI inflation forecasts. The ARMA model is used as the benchmark for each of the forecasts and therefore its MSFEs are expressed in absolute terms. The forecast errors of the other specifications are presented as the MSFEs of that specification relative to the MSFEs of the benchmark model. Therefore, MSFEs more than 1 imply larger forecast errors than those from the ARMA model. The lower the relative MSFEs, the better the forecasts.

Table 3 and 4 show the errors associated with forecasting headline import price inflation forecasts for the two sample periods ending in June 2012 and December 2007. For the

\footnotetext{
${ }^{6}$ In addition to the headline ("All commodities") import price index reported each month, the U.S. Department of Labor also reports a number of core import price indexes, specifically for "All commodities excluding food and fuels", "All commodities excluding petroleum", "All commodities excluding computers/semiconductors/petrol", "All commodities excluding fuels", and "All commodities excluding computers/semiconductors/fuels". The rationale for these measures of core import price inflation is much the same as that for the traditional exclusion type measures of core CPI or PPI inflation, namely that movements in the prices of certain categories of commodities or goods are excluded from months that they may have a large effect on the headline number and might not be indicative of underlying trends.

${ }^{7}$ We pick an estimation period of nine years as this generally captures a full business cycle, and is analogous to the length of time used in D'Agostino and Surico (2009). 12-year and a 5-year estimation periods were also considered, and the results were generally unchanged.
} 
benchmark ARMA model, 3 lags of import price inflation and an MA(3) of the error terms are used to forecast annualized import price inflation rates at the different horizons. The lag structure was selected by the Schwartz information criterion. ${ }^{8}$ Candidate predictors (core and trimmed mean import price inflation) enter the benchmark specification with 3 lags each. The first thing to note from Tables 3 and 4 is the enormous size of the MSFEs associated with forecasting import price inflation at short horizons. Even at longer horizons (two years) the errors are comparable in magnitude to the series being forecast. The results in Table 3 indicate that both the traditional ("All commodities excluding petroleum") measure of core import price inflation and the trimmed-mean measure of core import price inflation have little or no predictive power for headline import price inflation over and above that provided by the simple ARMA(3,3) model for the forecast period ending in June 2012. When the sample is restricted to the Great Moderation period when macroeconomic conditions were fairly stable, the forecast performance improve slightly but not by a significant amount (by 10 percent or less) at the 3, 9, 12, 18 and 24-month horizons.

Unlike what Bryan and Cecchetti (1994) found for trimmed-mean consumer price inflation measures, trimmed-mean import price inflation measures do not significantly help forecast headline import price inflation, and for the most part, underperform the (already poorly performing) ARMA model.

\footnotetext{
${ }^{8}$ Selection of optimal lag structure for the benchmark model is robust to using the Akaike information criterion.
} 
Table 3: Out-of-Sample Forecasts for Import Price Inflation: 2002-2012

\begin{tabular}{|c|c|c|c|c|c|c|c|}
\hline \multicolumn{8}{|c|}{ Import Price Inflation } \\
\hline \multicolumn{8}{|c|}{ Mean Square Forecasts Errors (MSFE) - Jan. 2002 : June 2012} \\
\hline & \multicolumn{7}{|c|}{ Horizon $h$} \\
\hline & 1 & 3 & 6 & 9 & 12 & 18 & 24 \\
\hline & \multicolumn{7}{|c|}{ Absolute MSFEs } \\
\hline \multirow[t]{2}{*}{ Benchmark model: ARMA (3,3) } & 219.93 & 26.66 & 12.67 & 7.39 & 5.33 & 2.63 & 1.82 \\
\hline & \multicolumn{7}{|c|}{ Relative MSFEs } \\
\hline$x_{t}=$ Core Import Prices ("Ex. Petroleum") & 1.06 & 0.95 & 1.08 & 1.13 & 1.36 & 1.36 & 1.36 \\
\hline$x_{t}=\bar{\mu}_{t \mid t-1}\left(\alpha^{T}=0.05, \alpha^{B}=0.05\right)$ & 1.05 & 1.01 & 1.06 & 1.09 & 1.13 & 0.99 & 1.24 \\
\hline$x_{t}=\bar{\mu}_{t \mid t-1}\left(\alpha^{T}=0.10, \alpha^{B}=0.10\right)$ & 1.06 & 0.94 & 1.12 & 1.17 & 1.07 & 0.97 & 0.96 \\
\hline$x_{t}=\bar{\mu}_{t \mid t-1}\left(\alpha^{T}=0.15, \alpha^{B}=0.15\right)$ & 1.03 & 1.02 & 1.09 & 1.14 & 1.25 & 1.13 & 1.10 \\
\hline$x_{t}=\bar{\mu}_{t \mid t-1}\left(\alpha^{T}=0.48, \alpha^{B}=0.39\right)$ & 1.06 & 1.02 & 1.04 & 1.05 & 1.04 & 1.26 & 1.27 \\
\hline$x_{t}=\bar{\mu}_{t \mid t-1}\left(\alpha^{T}=0.40, \alpha^{B}=0.42\right)$ & 1.07 & 1.00 & 1.02 & 1.11 & 1.02 & 1.13 & 1.33 \\
\hline$x_{t}=\bar{\mu}_{t \mid t-1}\left(\alpha^{T}=0.37, \alpha^{B}=0.29\right)$ & 1.06 & 1.17 & 1.16 & 1.35 & 1.22 & 1.20 & 1.74 \\
\hline$x_{t}=\bar{\mu}_{t \mid t-1}\left(\alpha^{T}=0.50, \alpha^{B}=0.50\right)($ Median $)$ & 1.03 & 0.98 & 1.07 & 1.06 & 1.12 & 1.19 & 1.71 \\
\hline
\end{tabular}

Table 4: Out-of-Sample Forecasts for Import Price Inflation: 2002-2007

\begin{tabular}{|c|c|c|c|c|c|c|c|}
\hline \multicolumn{8}{|c|}{ Import Price Inflation } \\
\hline \multicolumn{8}{|c|}{ Mean Square Forecasts Errors (MSFE) - Jan. 2002 : Dec. 2007} \\
\hline & \multicolumn{7}{|c|}{ Horizon $h$} \\
\hline & 1 & 3 & 6 & 9 & 12 & 18 & 24 \\
\hline & \multicolumn{7}{|c|}{ Absolute MSFEs } \\
\hline \multirow[t]{2}{*}{ Benchmark model: ARMA (3,3) } & 153.31 & 17.71 & 5.95 & 3.75 & 2.75 & 1.95 & 1.98 \\
\hline & \multicolumn{7}{|c|}{ Relative MSFEs } \\
\hline$x_{t}=$ Core Import Prices ("Ex. Petroleum") & 1.08 & 0.96 & 1.31 & 1.08 & 1.13 & 1.19 & 1.48 \\
\hline$x_{t}=\bar{\mu}_{t \mid t-1}\left(\alpha^{T}=0.05, \alpha^{B}=0.05\right)$ & 1.08 & 1.04 & 1.06 & 1.02 & 1.12 & 0.94 & 1.31 \\
\hline$x_{t}=\bar{\mu}_{t \mid t-1}\left(\alpha^{T}=0.10, \alpha^{B}=0.10\right)$ & 1.07 & 0.97 & 1.12 & 1.09 & 1.12 & 0.95 & 0.84 \\
\hline$x_{t}=\bar{\mu}_{t \mid t-1}\left(\alpha^{T}=0.15, \alpha^{B}=0.15\right)$ & 1.10 & 0.99 & 1.12 & 1.13 & 1.09 & 0.99 & 0.94 \\
\hline$x_{t}=\bar{\mu}_{t \mid t-1}\left(\alpha^{T}=0.48, \alpha^{B}=0.39\right)$ & 1.07 & 0.99 & 1.08 & 1.03 & 1.03 & 1.57 & 1.53 \\
\hline$x_{t}=\bar{\mu}_{t \mid t-1}\left(\alpha^{T}=0.40, \alpha^{B}=0.42\right)$ & 1.11 & 0.97 & 1.07 & 0.98 & 0.89 & 1.06 & 1.45 \\
\hline$x_{t}=\bar{\mu}_{t \mid t-1}\left(\alpha^{T}=0.37, \alpha^{B}=0.29\right)$ & 1.01 & 0.97 & 1.13 & 1.02 & 1.04 & 1.16 & 2.21 \\
\hline$x_{t}=\bar{\mu}_{t \mid t-1}\left(\alpha^{T}=0.50, \alpha^{B}=0.50\right)($ Median $)$ & 1.06 & 0.96 & 1.14 & 1.01 & 0.97 & 1.33 & 2.40 \\
\hline
\end{tabular}


Table 5 and 6 show the forecast errors of annualized CPI inflation using an autoregressive model and those augmented with headline and core measures of imports inflation. The benchmark model includes 2 lags of CPI inflation and an MA(3) of the error terms. An additional 3 lags of each of the imports inflation measures are considered in the remaining models. Table 5 indicates that imports inflation produce errors that are slightly more accurate than the ARMA benchmark model at the 1, 12, and 18-month horizons for the forecasting sample that includes the Great Recession. For the 24-month horizon, import prices provide no information for CPI inflation. However, when the MSFEs sample is restricted to the period ending in 2007, interesting results emerge as shown in Table 6. There are substantial improvements in the forecasts in horizons 12 and 18. Among the three import inflation measures used to forecast CPI inflation, some of the trimmed-mean forecasts provide the smallest MSFEs at the 1, 3, 12, and 18 month horizons. At $h=6$, all imports excluding petroleum provides the best forecast. Trimmed-mean inflation measures improve the accuracy of the benchmark model by up to $60-70$ percent at the $h=12$ and 18 -month horizon, and the different degrees of trimming evaluated suggest there is a range of trims that outperform the exclusion core measure of imports inflation. 
Table 5: Out-of-Sample Forecasts for Headline CPI Inflation: 2002-2012 CPI Headline Inflation Forecasts

\begin{tabular}{|c|c|c|c|c|c|c|c|}
\hline \multicolumn{8}{|c|}{ CPI Headline Inflation Forecasts } \\
\hline \multicolumn{8}{|c|}{ Mean Square Forecasts Errors (MSFE) - Jan. 2002 : June 2012} \\
\hline & \multicolumn{7}{|c|}{ Horizon $h$} \\
\hline & 1 & 3 & 6 & 9 & 12 & 18 & 24 \\
\hline & \multicolumn{7}{|c|}{ Absolute MSFEs } \\
\hline Benchmark model: ARMA(2,3) & 14.01 & 1.73 & 0.58 & 0.30 & 0.30 & 0.20 & 0.07 \\
\hline & \multicolumn{7}{|c|}{ Relative MSFEs } \\
\hline$x_{t}=$ Core Import Prices ("Ex. Petroleum") & 1.05 & 0.99 & 0.97 & 1.09 & 0.69 & 0.65 & 13.69 \\
\hline$x_{t}=$ All Commodities Import Prices & 0.96 & 0.98 & 1.04 & 1.07 & 0.77 & 0.67 & 2.13 \\
\hline$x_{t}=\bar{\mu}_{t \mid t-1}\left(\alpha^{T}=0.05, \alpha^{B}=0.05\right)$ & 0.97 & 1.01 & 1.08 & 1.04 & 0.70 & 0.83 & 24.91 \\
\hline$x_{t}=\bar{\mu}_{t \mid t-1}\left(\alpha^{T}=0.10, \alpha^{B}=0.10\right)$ & 0.94 & 1.03 & 1.03 & 1.03 & 0.71 & 0.74 & 12.90 \\
\hline$x_{t}=\bar{\mu}_{t \mid t-1}\left(\alpha^{T}=0.15, \alpha^{B}=0.15\right)$ & 0.97 & 1.03 & 1.12 & 1.03 & 0.74 & 0.79 & 1.56 \\
\hline$x_{t}=\bar{\mu}_{t \mid t-1}\left(\alpha^{T}=0.48, \alpha^{B}=0.39\right)$ & 1.05 & 1.02 & 1.08 & 1.20 & 0.75 & 0.56 & 1.38 \\
\hline$x_{t}=\bar{\mu}_{t \mid t-1}\left(\alpha^{T}=0.40, \alpha^{B}=0.42\right)$ & 1.03 & 0.99 & 1.03 & 1.20 & 0.75 & 0.61 & 1.04 \\
\hline$x_{t}=\bar{\mu}_{t \mid t-1}\left(\alpha^{T}=0.37, \alpha^{B}=0.29\right)$ & 1.07 & 1.05 & 1.49 & 1.59 & 1.03 & 0.69 & 2.33 \\
\hline$x_{t}=\bar{\mu}_{t \mid t-1}\left(\alpha^{T}=0.50, \alpha^{B}=0.50\right)($ Median $)$ & 1.02 & 0.98 & 1.04 & 1.15 & 0.72 & 0.62 & 1.62 \\
\hline
\end{tabular}

Table 6: Out-of-Sample Forecasts for Headline CPI Inflation: 2002-2007 CPI Headline Inflation Forecasts

\begin{tabular}{|l|l|l|l|l|l|l|l|}
\hline \multicolumn{7}{|c|}{ CPI Headline Inflation Forecasts } \\
\hline \hline \multicolumn{7}{|c|}{ Horizon $h$} \\
\hline \hline Horizon & \multicolumn{7}{|c|}{ Absolute MSFEs } \\
\hline & $\mathbf{1}$ & $\mathbf{3}$ & $\mathbf{6}$ & $\mathbf{9}$ & $\mathbf{1 2}$ & $\mathbf{1 8}$ & $\mathbf{2 4}$ \\
\hline & \multicolumn{7}{|c|}{ Relative MSFEs } \\
\hline Benchmark model: ARMA(2,3) & $\mathbf{1 0 . 0 0}$ & $\mathbf{1 . 1 7}$ & $\mathbf{0 . 3 1}$ & $\mathbf{0 . 1 4}$ & $\mathbf{0 . 3 1}$ & $\mathbf{0 . 1 7}$ & $\mathbf{0 . 0 4}$ \\
\hline & \multicolumn{7}{|c|}{ ARorecasts Errors (MSFE) - Jan. 2002 : Dec. 2007 } \\
\hline$x_{t}=$ Core Import Prices ("Ex. Petroleum") & 1.18 & 1.01 & 0.99 & 1.07 & 0.42 & 0.66 & 34.38 \\
$x_{t}=$ All Commodities Import Prices & 1.06 & 1.01 & 1.08 & 1.06 & 0.41 & 0.37 & 4.38 \\
$x_{t}=\bar{\mu}_{t \mid t-1}\left(\alpha^{T}=0.05, \alpha^{B}=0.05\right)$ & 1.05 & 1.06 & 1.04 & 0.97 & 0.41 & 0.83 & 79.77 \\
$x_{t}=\bar{\mu}_{t \mid t-1}\left(\alpha^{T}=0.10, \alpha^{B}=0.10\right)$ & 1.00 & 1.03 & 1.02 & 0.95 & 0.41 & 0.52 & 40.06 \\
$x_{t}=\bar{\mu}_{t \mid t-1}\left(\alpha^{T}=0.15, \alpha^{B}=0.15\right)$ & 1.05 & 1.03 & 1.02 & 0.90 & 0.42 & 0.54 & 2.68 \\
$x_{t}=\bar{\mu}_{t \mid t-1}\left(\alpha^{T}=0.48, \alpha^{B}=0.39\right)$ & 1.06 & 0.99 & 1.03 & 1.46 & 0.38 & 0.32 & 2.08 \\
$x_{t}=\bar{\mu}_{t \mid t-1}\left(\alpha^{T}=0.40, \alpha^{B}=0.42\right)$ & 1.03 & 0.95 & 1.00 & 1.10 & 0.43 & 0.29 & 1.07 \\
$x_{t}=\bar{\mu}_{t \mid t-1}\left(\alpha^{T}=0.37, \alpha^{B}=0.29\right)$ & 1.09 & 0.99 & 1.02 & 1.11 & 0.36 & 0.29 & 4.14 \\
$x_{t}=\bar{\mu}_{t \mid t-1}\left(\alpha^{T}=0.50, \alpha^{B}=0.50\right)$ (Median) & 1.05 & 1.01 & 1.01 & 1.21 & 0.37 & 0.52 & 2.89 \\
\hline
\end{tabular}




\section{Conclusions}

This paper explored the statistical properties of the cross-section distribution of U.S. import prices. We showed that the distribution is characterized by the same fat-tails property that is found in the cross-section distribution of U.S. consumer prices. This property suggests that limited influence estimators of the mean of the distribution are superior to conventional measures, and that a limited influence estimator of core import price inflation might outperform conventional measures of core import price inflation. Limited influence estimators of core import price inflation are attractive from the perspective of having a basis in statistical theory, and because the choice of which prices to include and which to exclude in the core measure is based on the behavior of prices each month, and not on an arbitrary one-time decision (as with the traditional exclusion type "Ex. Food and Energy" measures of core) to always include some prices and always exclude others. Specifically, we examined whether these limited influence measures had any incremental predictive power for headline import price and headline consumer price inflation. We found that during periods of macroeconomic stability as in the Great Moderation, trimmed mean import inflation measures have some incremental predictive power for headline CPI inflation, but offer little information for future overall import price inflation. The traditional core import price measure that excludes petroleum - as well as the headline import price series - also provide some value in forecasting CPI inflation, but are outperformed by the trimmed-mean inflation measures at most horizons we evaluated. Core measures of import price inflation provide little or no predictive power for headline U.S. import price inflation.

In terms of directions for future research, our findings suggest a number of possibilities. To begin with, it would be interesting to know if the properties of the cross-section distribution of import prices that we document for the United States are also present in the cross-section distributions of import prices for other countries, especially countries that are more open to international trade than the United States. It would also be interesting to know if the properties of the cross-section distribution of import prices have changed over time as the

world has become more economically integrated as a result of globalization. And finally, 
it would be interesting to see whether limited influence estimators of core import price inflation have incremental forecasting power for headline inflation in other countries besides the United States. Monetary policy is of necessity forward looking, and inflation forecasts are a crucial input to monetary policymaking everywhere. However, it is well known that accurate inflation forecasts are hard to come by and that it is difficult to beat forecasts generated by a simple AR model of inflation. To the extent that the findings we document here prove to be robust, they will be a useful input to policymaking. 


\section{Appendix: Computing trimmed mean import price inflation}

Each month's trimmed mean import price inflation rate is calculated using the following steps.

1. Compute the monthly percent change (without annualization) in each component import price index.

2. Sort the percent changes in price from smallest to largest, and sort the relative importance weights for each component along with the price changes. The ordered inflation rates and weights are denoted, respectively, $\pi_{i}$ and $w_{i}, i=1,2,3 \ldots, n$.

3. Form the cumulative sum of the sorted relative importance weights for each ordered price change $i$. For example, the cumulative weight associated with $\pi_{4}$, the fourthranked price change, equals $w_{1}+w_{2}+w_{3}+w_{4}$

4. Exclude those percent changes in price for which the cumulative weight is either equal or more than $\alpha$, the percent you would like to trim to compute a $(\alpha)$-trimmed mean inflation,

i.e. let $i_{t}(\alpha)=\min \left\{I: \sum_{i=1}^{I} w_{i, t} \geq \alpha\right\}$ for $\alpha \in[0,100]$

5. A trimmed mean import price inflation $(\alpha, \beta)$ that drops $\alpha \%$ of the weight from the left tail of each month's distribution and $\beta \%$ of the weight from the right tail of each month's distribution is computed as

$\pi_{i}^{(\alpha, \beta)}=\frac{1}{100-\alpha-\beta} \sum_{i=i_{t}(\alpha)}^{i_{t}(100-\beta)} w_{i, t} \pi_{i, t}$ for each date $t$ 
Below is an example of the computation of trimmed mean inflation measures. The table lists sample inflation data for six import price components for month $t$.

\begin{tabular}{|l|l|l|l|l|l|l|}
\hline & \multicolumn{5}{|c|}{ Import Price Components } \\
\hline & $\mathrm{A}$ & $\mathrm{B}$ & $\mathrm{C}$ & $\mathrm{D}$ & $\mathrm{E}$ & $\mathrm{F}$ \\
\hline $\mathrm{m} / \mathrm{m} \%$ import price inflation ordered from smallest to largest & 1.25 & 1.80 & 2.50 & 3.20 & 3.60 & 4.50 \\
\hline Corresponding weights in import price index & 0.05 & 0.04 & 0.25 & 0.38 & 0.18 & 0.10 \\
\hline Cumulative weights & 0.05 & 0.09 & 0.34 & 0.72 & 0.90 & 1.00 \\
\hline
\end{tabular}

To compute a trimmed mean inflation that truncates $10 \%$ on each side, start by eliminating price changes whose cumulative weights fall outside the 0.1 and 0.9 range, i.e. only consider the price changes that are in the center of the price distribution after trimming $10 \%$ from both left and right tail of the distribution. Product A, with the smallest price change and with a weight of 0.05 is eliminated. Product B is also eliminated because its cumulative weight is within than the 0.1 needed to be trimmed. Products C, D and E are retained as their cumulative weights fall within the 0.1 and 0.9 range. Product $\mathrm{F}$ is eliminated as its weight is exactly 0.1 , the percent to be trimmed from the right tail of the import price distribution.

The new weighted average is computed using price changes of products $\mathrm{C}, \mathrm{D}$, and $\mathrm{E}$ i.e. $(2.50 \times 0.25)+(3.20 \times 0.38)+(3.60 \times 0.18)=2.489$. This average is normalized by dividing by the sum of the remaining weights $(0.25+0.38+0.18)=0.81$

Therefore, the weighted average (a 10\% trimmed mean measure) for month $t$ is $\frac{2.489}{0.81}=$ 3.07 


\section{References}

D'Agostino Antonello, and Paolo Surico, 2009. Does global liquidity help forecast U.S. inflation? Journal of Money, Credit, and Banking, 41, 479-489.

Bean, Charles, 2006. Commentary: Impact of Globalization on Monetary Policy. In Federal Reserve Bank of Kansas City The New Economic Geography: Effects and Policy Implications. Kansas City: Federal Reserve Bank of Kansas City.

Bryan, Michael F. and Stephen G. Cecchetti, 1994. Measuring core inflation. In N.G. Mankiw (ed.) Monetary Policy. Chicago: University of Chicago Press.

Bryan, Michael F., Stephen G. Cecchetti and Rodney L. Wiggins, 1997. Efficient inflation estimation. NBER Working Paper 6183.

Bryan, Michael F. Bryan and Christopher J. Pike, 1991. Median price changes: An alternative approach to measuring current monetary inflation. Federal Reserve Bank of Cleveland Economic Commentary.

Dolmas, Jim, 2005. Trimmed mean PCE inflation. Federal Reserve Bank of Dallas Research Department Working Paper 0506.

Gordon, Robert J., 2011. The history of the Phillips Curve: Consensus and bifurcation. Economica, 78, 10-50.

Martínez-García, Enrique and Mark A. Wynne, 2010. The Global Slack Hypothesis. Federal Reserve Bank of Dallas Staff Papers, number 10.

— and —, 2012. Global slack as a determinant of U.S. inflation. Federal Reserve Bank of Dallas Globalization and Monetary Policy Institute Working Paper no. 123.

Phillips. A. W., 1958. The relationship between unemployment and the rate of change of money wages in the United Kingdom 1861-1957. Economica 25 (100): 283-299. 
Roger, Scott, 1997. A robust measure of core inflation in New Zealand 1949-96. Discussion Paper G97/7, Reserve Bank of New Zealand.

Stock, James H., and Mark W. Watson, 1999. Forecasting inflation. Journal of Monetary Economics, 44, 293-335.

Vega, Juan Luis, and Mark A. Wynne, 2003. A first assessment of some measures of core inflation for the euro area. German Economic Review, 4, 269-306.

Wynne, Mark A., 2008. Core inflation: A review of some conceptual issues. Federal Reserve Bank of St. Louis Economic Review, 90(3), Part 2, 205-228.

Wynne, Mark A., and Genevieve R. Solomon, 2007. Obstacles to measuring global output gaps. Federal Reserve Bank of Dallas Economic Letter, volume 2, number 3. 
Figure 1: Distributions of Monthly Price Changes

Figure 1a. Standard Deviation

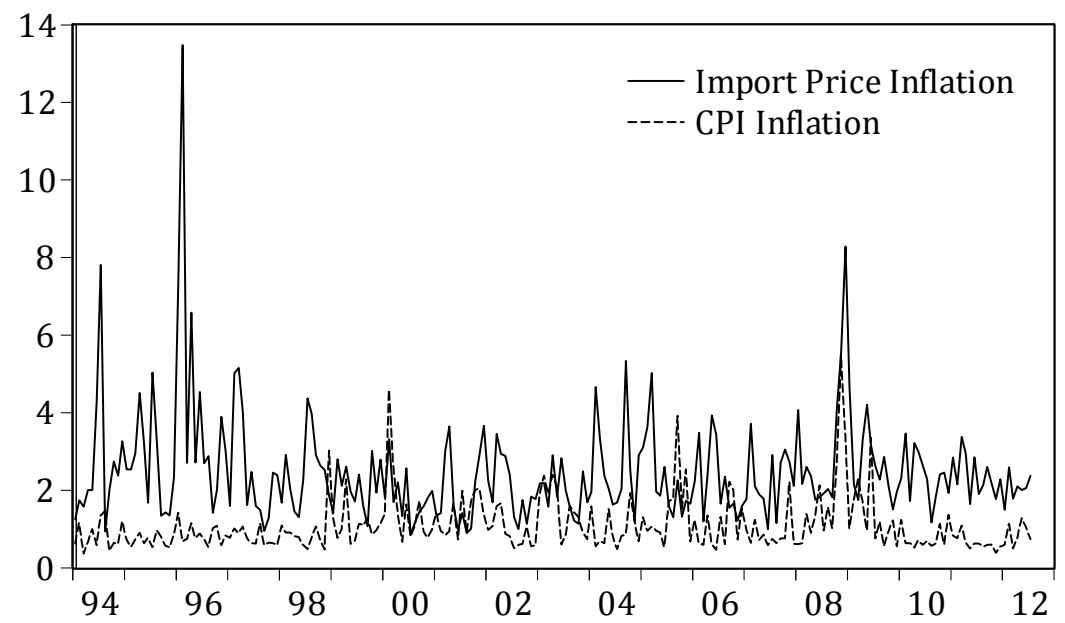

Figure 1b. Skewness

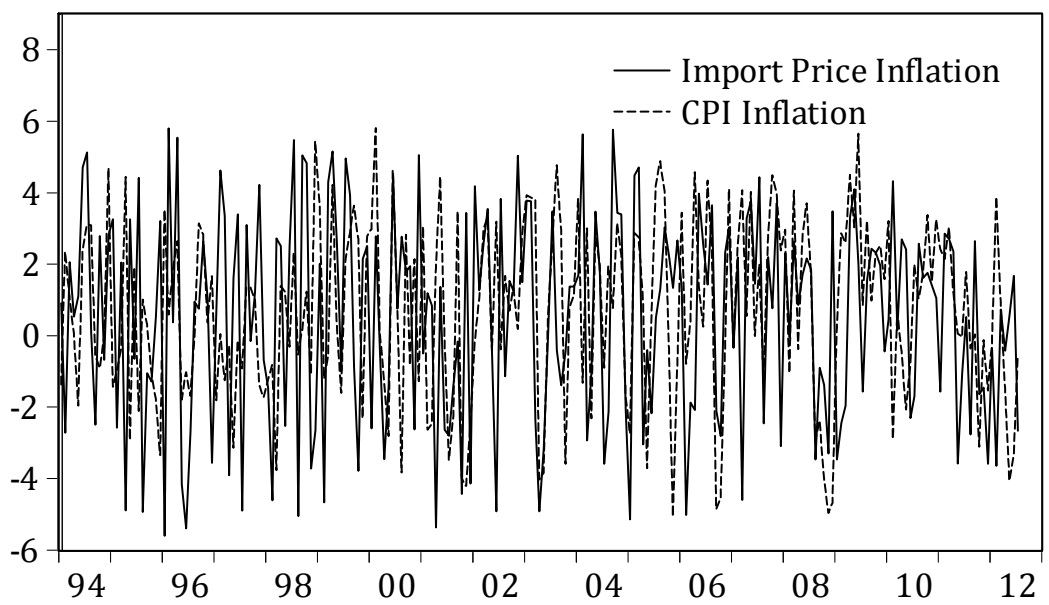

Figure 1c. Kurtosis

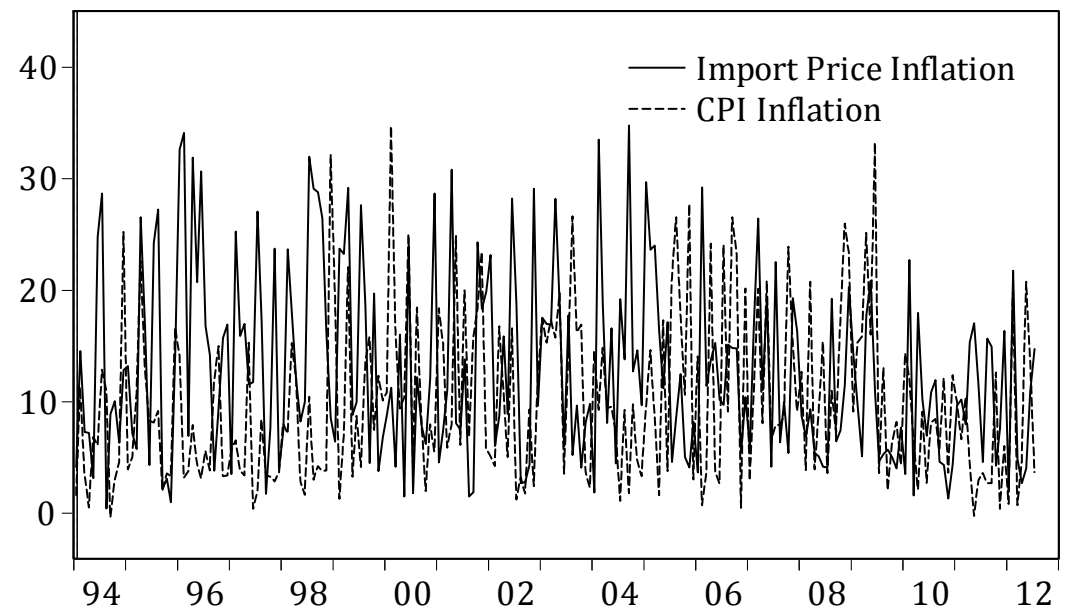

